University of Massachusetts Amherst

ScholarWorks@UMass Amherst

Chemistry Department Faculty Publication Series

Chemistry

1979

\title{
Analytical Aspects of Absorption Spectroelectrochemistry at a Platinum Electrode- I study of Metal Ions
}

Julian Tyson

University of Massachusetts Amherst

T. S. West

Follow this and additional works at: https://scholarworks.umass.edu/chem_faculty_pubs

Part of the Analytical Chemistry Commons

\section{Recommended Citation}

Tyson, Julian and West, T. S., "Analytical Aspects of Absorption Spectroelectrochemistry at a Platinum Electrode- I study of Metal Ions" (1979). Talanta. 1375.

Retrieved from https://scholarworks.umass.edu/chem_faculty_pubs/1375

This Article is brought to you for free and open access by the Chemistry at ScholarWorks@UMass Amherst. It has been accepted for inclusion in Chemistry Department Faculty Publication Series by an authorized administrator of ScholarWorks@UMass Amherst. For more information, please contact scholarworks@library.umass.edu. 


\title{
ANALYTICAL ASPECTS OF ABSORPTION SPECTROELECTROCHEMISTRY AT A PLATINUM ELECTRODE-I STUDY OF METAL IONS
}

\author{
J. F. TYSON* and T. S. WeST† \\ Department of Chemistry, Imperial College of Science and Technology, London S.W.7
}

(Received 6 March 1978. Accepted 29 June 1978)

\begin{abstract}
Summary-An apparatus has been built with which the intensity of a light-beam passing at grazing incidence over a platinum electrode can be monitored. The absorption of light which occurs during the electrolysis of dilute aqueous metal ion solutions has been studied as a function of a number of parameters including wavelength, potential difference and concentration. The theories of metal deposition and processes occurring at the electrode surface and in the diffusion layer have been examined and a mechanism for the production of the absorbing species in terms of increase in $\mathrm{pH}$ of the catholyte is proposed. The analytical potential of the technique is discussed.
\end{abstract}

The combination of optical techniques such as internal refection spectroscopy, ellipsometry, transmission spectroscopy, specular reflection spectroscopy, with electrochemical methods such as chronoamperometry, chronopotentiometry and linear sweep voltammetry provides powerful methods for the elucidation of the mechanism of electrode reactions, identification of intermediates, and nature of adsorbed species and the determination of diffusion coefficients and rate constants. ${ }^{1-3}$

From the analytical point of view, those methods in which the concentration of an electroactive species rather than the nature of the electrode surface is monitored during electrolysis, are of interest. These spectroelectrochemical methods are based on the use of an optically transparent electrode (OTE). Two types of electrodes are in common use, namely, (1) thin-film electrodes made by coating a transparent substrate with metals (platinum, gold, silver, mer(vry) $)^{4-6}$ or doped oxides (tin oxide or indium oxide $)^{7-9}$ and (2) minigrid electrodes usually made by etching rectangular holes in fine metal foils (usually gold). ${ }^{10}$ The methods of monitoring the electroactive species at these electrodes are (1) normal transmission spectroscopy (NTS), where the absorbance of a lightbeam passing at right angles through the electrode surface is monitored and (2) internal reflection spectroscopy (IRS). The basis of IRS is the fact that when a light-beam undergoes total internal reflection at a phase boundary, the light-beam actually penetrates the rarer medium. ${ }^{11}$ Thus, when a beam of light traverses a thin-layer OTE, every time an internal reflection occurs at the film-solution interface, the lightbeam passes into the solution for a few $\mathrm{nm}$, where

- Present address: Department of Chemistry, University of Technology, Loughborough, U.K.

† Present address: Macaulay Institute for Soil Research, Craigiebuckler, Aberdeen, Scotland. it may be absorbed by species close to the electrode surface. The complete (though somewhat complex) theory for the three-phase case (i.e., glass, film, solution) has been given by Hansen. ${ }^{1,12}$

Normal transmission spectroscopy at thin-film OTEs was first described by Kuwana et al. ${ }^{13.14}$ The scope of the method is shown in two recent reviews. ${ }^{2,15}$ NTS at minigrid OTEs is described by Murray et al. ${ }^{10}$ These spectroelectrochemical methods have also been used in conjunction with thin-layer cells. These are narrow cells (typically $10^{-2} \mathrm{~mm}$ ) with a small electrolyte volume (a few $\mu \mathrm{l}$ ) so electrolysis becomes exhaustive after a few hundred msec. The theory and applications of these types of cells have been reviewed. ${ }^{16,17}$ The use of this type of cell with gold minigrid electrodes is described by Murray ${ }^{18}$ and with platinum film electrodes by Reilley. ${ }^{4}$

The combination of IRS and thin film OTEs was first reported by Kuwana et al. ${ }^{19}$ The scope of the technique is shown in a slightly later publication. ${ }^{20}$ The technique has been extensively applied in the determination of reaction mechanisms, see for example Grant and Kuwana. ${ }^{21}$ So far there have been no applications of these spectroelectrochemical techniques in quantitative analysis, possibly because of the inherent lack of sensitivity of the methods due to the very short path-length containing the absorbing species in the solution which the light-beam actually traverses.

In this paper, a spectroelectrochemical method is described in which a narrow light-beam is passed at grazing incidence across the surface of a smooth platinum electrode. The absorbance is monitored as dilute aqueous metal ion solutions are electrolysed. Preliminary results describing the absorbance phenomena observed have already been reported. ${ }^{22}$ Here detailed results and discussion are presented to determine the 


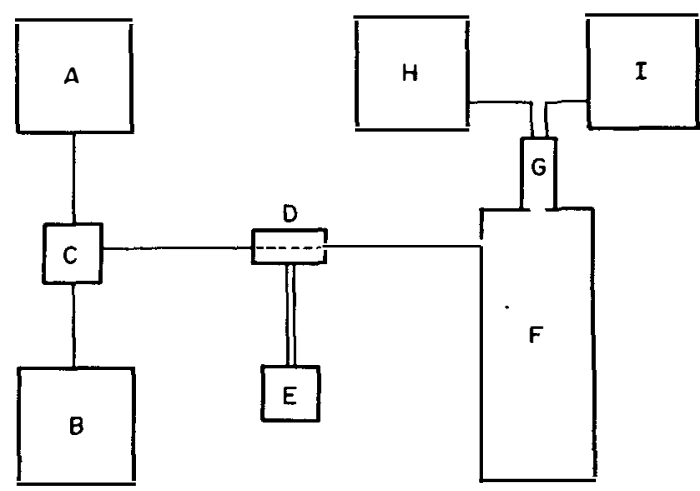

Fig. 1. Schematic diagram of apparatus. A, Power supply for deuterium lamp. B, Power supply for tungsten lamp. C, Lamp housing. D, Cell, E, Potentiostatic waveform source. F, Monochromator. G, PMT. H, EHT supply for PMT, I, Chart recorder.

nature of the electrode process observed and to assess the analytical potential of the method.

\section{EXPERIMENTAL}

\section{Apparatus}

Spectrophotometer. A simple ultraviolet/visible apparatus (see Fig. 1) was built from the following components: a deuterium lamp (Cathodeon type C70-2V-S) with Unicam SP500 lamp supply, a tungsten filament lamp run from a regulated power supply (APT Electronic Industries type TCU 550), a monochromator (Optika CE4), a photomultiplier (EMI type 6256B) with power supply (Brandenburg type 475R), a chart recorder (Smith's Industries Servoscribe type RE11.20).

Cell assembly. This is shown in Fig. 2. A 2-cm silica cell was used. containing two polished platinum plate electrodes. The cell was fitted with an inlet for oxygen-free nitrogen, an outlet for removal of solutions by suction and an agar $/ \mathrm{KCl}$ salt bridge to a saturated calomel reference electrode (SCE). The cell assembly was mounted on vertical and horizontal racking movements, in turn mounted on an optical bar (Ealing Tri-rack). Fixed horizontal slits were mounted on either side of the cell. Vertical movement of the cell ensured that the light-beam was of a suitable height (approx. $0.5 \mathrm{~mm}$ ) whereas lateral movement ensured that light passed only over the electrode surface.

Potential source. A potentiostatic waveform source was used (Chemtrix type 804 ). This provided ramp or step functions in either a two-or three-electrode mode of operation.

\section{Reagents}

Stock $1 \%$ metal ion solutions were prepared by dissolving the appropriate amount of the analytical-reagent grade salt (usually chloride or sulphate) in $100 \mathrm{ml}$ of distill water. A stock $(0.3 M)$ background electrolyte solution prepared by dissolving the appropriate amount of analytical grade potassium sulphate in 1 litre of distilled watz Working solutions of typically $10 \mathrm{ppm}$ metal in $0.03 \mathrm{~V}$ potassium sulphate were prepared daily by dilution.

\section{Procedure}

The function generator was preset so that when it $n$ switched on a constant potential was applied to the elatrode in the light-path (the working electrode) so that this electrode became the cathode. A 5-ml aliquot of the worling solution, the bulk of which was continuously deaerate with oxygen-free nitrogen, was transferred to the cell and deaerated further for $60 \mathrm{sec}$. The solution was kept und a nitrogen blanket throughout. The gain of the system as adjusted so that at the required wavelength a setting $\mathrm{o}$ $0 \%$ absorption was obtained on the chart recorder, nit $100 \%$ absorption being obtained when the light-beam $\mathrm{n}_{2}$ interrupted by a piece of opaque material. The char recorder was started and the function generator switchet on to its preset value, then the absorption signal $n x$ recorded until a maximum was reached (typically $30 \mathrm{sect}$ The solution was removed from the cell by suction ant the working electrode cleaned by application of a high positive potential while the electrode was rinsed with bad. ground electrolyte solution. Potentials of up to $5.0 \mathrm{~V}$ nith respect to the counter-electrode were used. The electrods were finally rinsed with distilled water.

\section{RESULTS}

By use of the procedure above, the variation of absorbance with a number of experimental parameters was investigated for several metal ion solutions.

\section{Potential difference}

For those metals which gave rise to an absorbance signal, the results obtained were essentially similar. The results for cobalt are shown in Fig. 3, and the results for the other metals in Table 1.

\section{Wavelength}

The absorption spectra obtained are shown in Fig 4 and the wavelengths of the absorption maxima are given in Table 1. These spectra are corrected for the absorbance obtained with the background electrolyte alone. This spectrum is shown in Fig. 5.

\section{Concentration}

At a suitable potential and wavelength the analyti-

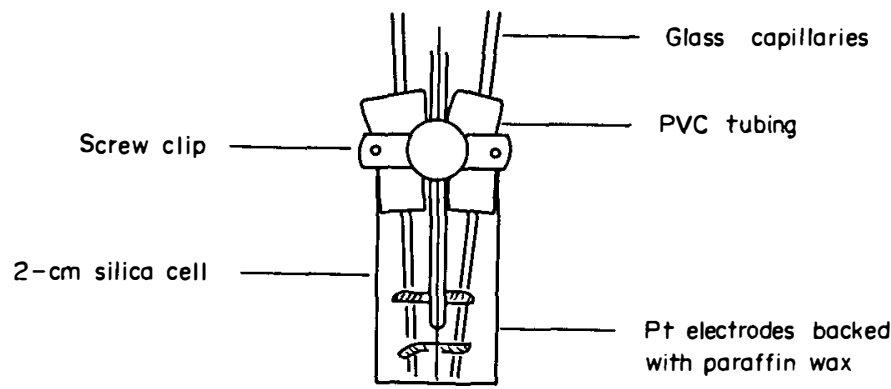

Fig. 2. Cell and electrode assembly. 


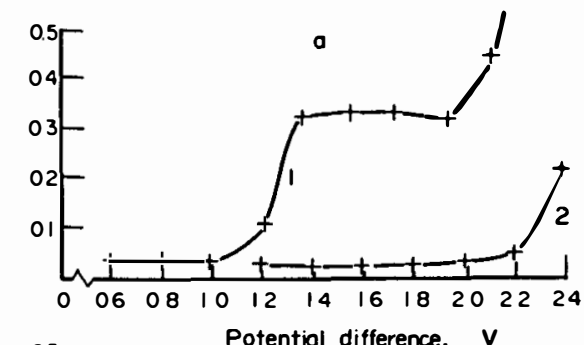

b
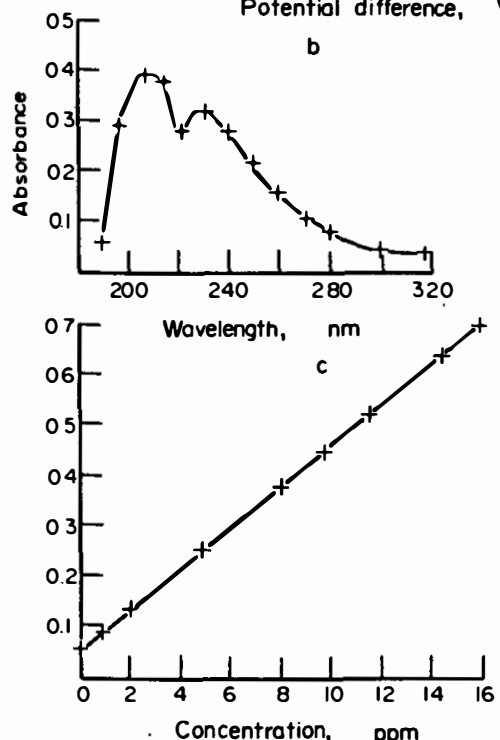

Fig. 3. Variation of absorbance with (a) potential difference, curve $1,10 \mathrm{ppm}$ cobalt at $225 \mathrm{~nm}$; curve 2, blank solution: (b) wavelength $(10 \mathrm{ppm}$ and $1.4 \mathrm{~V})$ : (c) concentration $(210 \mathrm{~nm}$, and $2.0 \mathrm{~V})$.

al growth curve for each metal was obtained. The linear region of the calibration curve and the sensitivity (concentration for $1 \%$ absorption) are given in Table 1.

\section{Distance from the electrode surface and time}

The variation of the absorbance with time as the electrode was moved progressively out of the lightbeam is shown in Fig. 6. The solution used was $10 \mathrm{ppm}$ cobalt. This type of relationship was shown by all the metals.

\section{Pretreatment of the electrode}

It is well known that a platinum electrode is not electrochemically inert $^{23}$ and various potential regions corresponding to hydrogen adsorption and desorption, oxide formation and oxide reduction can be identified. ${ }^{24}$ It is apparent that the conditions used to clean the electrode surface by anodic stripping in the procedure would have left the electrode surface coated with a layer of platinum oxide.

The effect of the pretreatment on the absorbance for $20 \mathrm{ppm}$ zinc (at $205 \mathrm{~nm}$ ) and for the background electrolyte alone (at $198 \mathrm{~nm}$ ) is shown in Table 2. The effect of the nature of the electrode surface at the start of the electrolysis is shown in Fig. $7 a, b$, for $20 \mathrm{ppm}$ cadmium and $0.03 \mathrm{M}$ potassium sulphate. In these experiments the first stage of the procedure was modified so that a linearly decreasing potential (with respect to the SCE) was applied to the working electrode. The potential sweep-rate used was $50 \mathrm{mV} / \mathrm{sec}$.

\section{Initial $\mathrm{pH}$ of the solution}

The effect of increasing the sulphuric acid concentration of the solution was studied for $10 \mathrm{ppm}$ cadmium and $0.03 \mathrm{M}$ potassium sulphate. The results are shown in Table 3. All the absorbances were measured at a potential of $-0.2 \mathrm{~V} v \mathrm{~s}$. the SCE.

\section{Change in $\mathrm{pH}$ near the electrode}

It is known that during electrolysis at inert electrodes the solution near the cathode becomes alkaline when hydrogen is evolved. ${ }^{25}$ The effect has been subjected to theoretical analysis. ${ }^{26-28}$ To follow any changes in $\mathrm{pH}$ near the working electrode a $10^{-3} \%$ solution of phenolphthalein in $0.03 \mathrm{M}$ potassium sulphate was used. The absorbance at $552 \mathrm{~nm}$ was followed, this being the absorbance maximum of the alkaline form of the indicator. The absorbance as a function of potential (linear sweep-rate $50 \mathrm{mV} / \mathrm{sec}$ ) is shown in Fig. 7c for an oxidized and a reduced electrode surface.

\section{Spectra of metal ions in alkaline solution}

The absorption spectra of the metal ion solutions in $0.03 \mathrm{M}$ potassium sulphate were recorded (Perkin-

Table 1. Summary of results

\begin{tabular}{|c|c|c|c|c|c|}
\hline Metal & $\begin{array}{c}\text { Plateau region of } \\
\text { absorbance } v s \text {. potential } \\
\text { variation, } V\end{array}$ & $\begin{array}{l}\text { Linear range of } \\
\text { calibration } \\
\text { curve, ppm }\end{array}$ & $\begin{array}{c}\text { Sensitivity, } \\
\text { ppm }\end{array}$ & $\begin{array}{c}\lambda_{\max } \text { at } \\
\text { electrode } \\
\text { surface, } n m\end{array}$ & $\begin{array}{c}\lambda_{\max } \text { in } \\
10^{-3} M \\
\text { KOH, } n m\end{array}$ \\
\hline $\mathrm{Cd}$ & - & $0-15$ & 0.09 & 215 & 215 \\
\hline Co & $1.4-2.0$ & $0-15$ & 0.11 & 210 & 212 \\
\hline $\mathrm{Gr}$ & $1.4-1.8$ & $0-8$ & 0.05 & 215 & 205 \\
\hline $\mathrm{Cu}$ & $1.6-2.0$ & $0-15$ & 0.10 & 235 & 237 \\
\hline $\mathrm{Fe}(\mathrm{II})$ & - & - & - & 270 & - \\
\hline $\mathrm{Fe}(\mathrm{III})$ & - & $0-10$ & 0.09 & 270,364 & 260,360 \\
\hline $\mathrm{Mn}$ & $1.9-2.0$ & $0-12$ & 0.08 & 210 & 215 \\
\hline $\mathrm{Ni}$ & $1.6-2.0$ & $0-20$ & 0.16 & 208 & 210 \\
\hline $\mathrm{Pb}$ & - & $20-50$ & 0.35 & 270 & 234 \\
\hline $\mathrm{Zn}$ & $0.9-1.8$ & $0-12$ & 0.08 & 207 & 207 \\
\hline
\end{tabular}



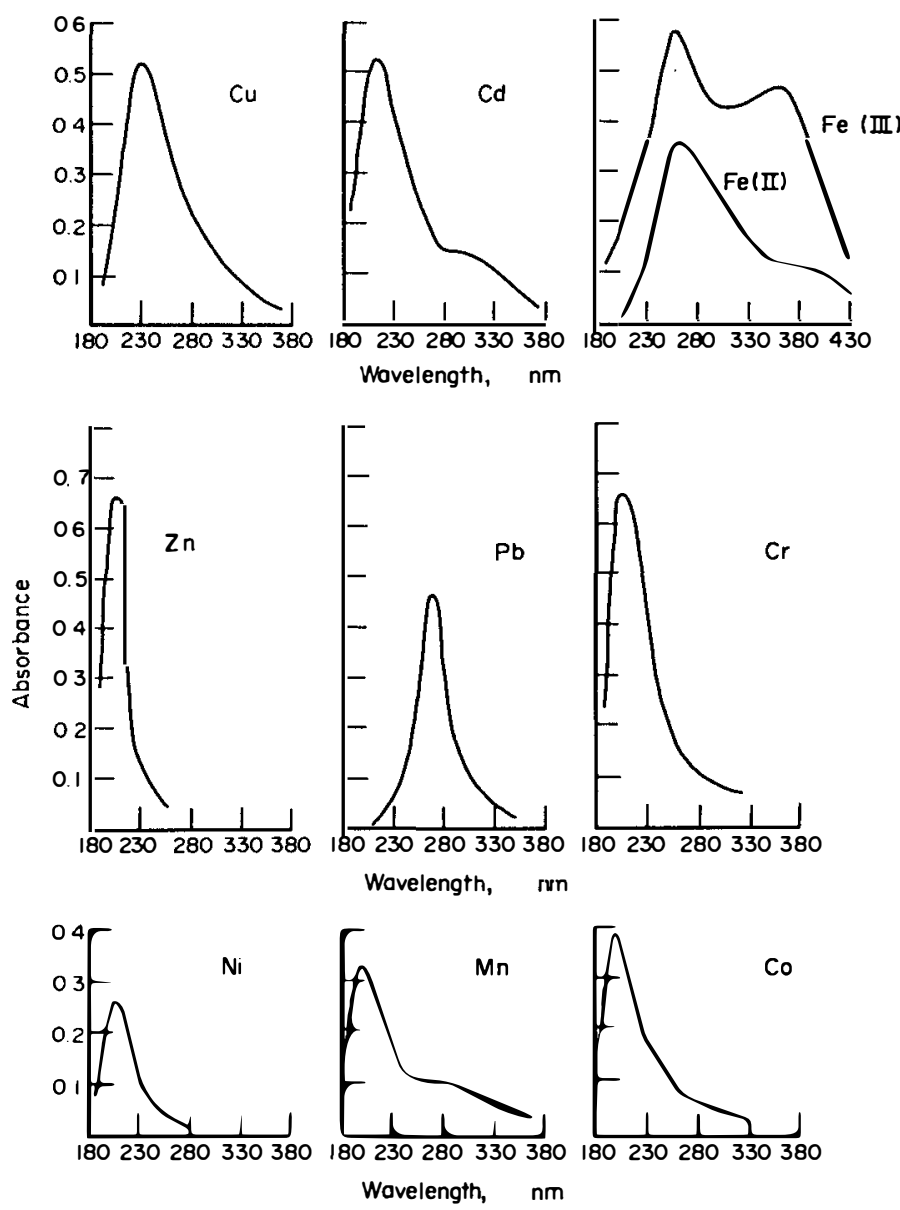

Fig. 4. Absorption spectra of electrogenerated species. All 10 ppm except $\mathrm{Fe}(\mathrm{II}), 5 \mathrm{ppm}$.

Elmer model 402 ultraviolet/visible spectrophotometer) immediately after the solution was made $10^{-3} M$ with respect to potassium hydroxide. The spectra are shown in Fig. 8. The absorbance maxima are given in Table 1.

\section{DISCUSSION}

The results show that undoubtedly the absorbance phenomena observed are due to a reaction or reac-

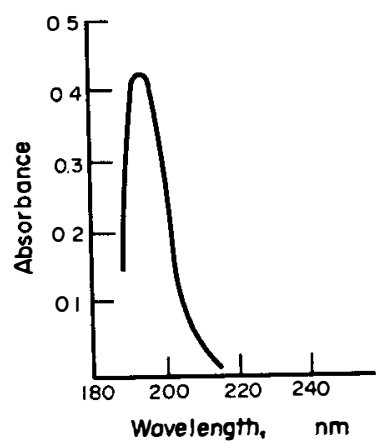

Fig. 5. Absorption spectrum of electrogenerated species from blank solution, $0.03 \mathrm{M} \mathrm{K}_{2} \mathrm{SO}_{4}$. tions at the electrode surface and that the absorbing product or products then diffuse away from the elec. trode.

Although the absorbances for the metal ion solvtions were found to be independent of the intensit? of the incident light-beam, this does not indicate whether the attenuation of the light-beam was by true absorption or Rayleigh scattering (i.e., by particles small in comparison with the wavelength of the inci-

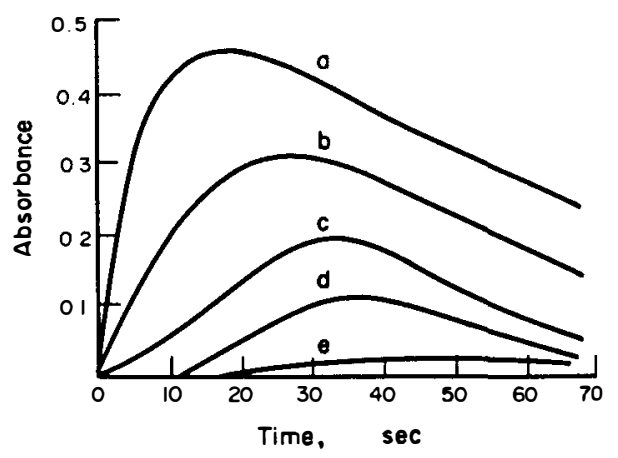

Fig. 6. Variation of absorbance with time for various dis. tances from the electrode surface. (a) $0.05,0.09,0.15$ and $0.20 \mathrm{~mm}$. (b) $0.80 \mathrm{~mm}$. (c) $1.40 \mathrm{~mm}$. (d) $1.80 \mathrm{~mm}$. (e) 2.20 $\mathrm{mm}$. 
Table 2. Effect of pretreatment

\begin{tabular}{|c|c|c|c|}
\hline \multicolumn{2}{|c|}{ Zinc solution } & \multicolumn{2}{|c|}{ Blank solution } \\
\hline$\underset{V}{\text { Pretreatment cycle, }}$ & $\begin{array}{c}205 \mathrm{~nm} \text { and } \\
-1.4 \mathrm{~V}\end{array}$ & $\underset{V}{\text { Pretreatment cycle, }}$ & $\begin{array}{c}200 \mathrm{~nm} \text { and } \\
-1.4 \mathrm{~V}\end{array}$ \\
\hline$+2.0,-2.0$ & 0.025 & 0.0 & 0.190 \\
\hline$+3.0,-3.0$ & 0.029 & +1.0 & 0.036 \\
\hline$+3.5,-3.5$ & 0.029 & +2.0 & 0.053 \\
\hline$+4.0,-4.0$ & 0.141 & +3.0 & 0.080 \\
\hline+4.0 & $>1$ & +4.0 & 0.152 \\
\hline+5.0 & $>1$ & +5.0 & 0.167 \\
\hline & & $+5.0,-0.5$ & 0.165 \\
\hline & & $+5.0,-1.0$ & 0.104 \\
\hline & & $+5.0,-1.5$ & 0.035 \\
\hline & & $+5.0,-2.0$ & 0.028 \\
\hline
\end{tabular}

dent light). Both of these phenomena give rise to values of $\log \phi_{0} / \phi_{1}$ (where $\phi_{0}$ is the incident radiant flux and $\phi_{1}$ is the transmitted radiant flux) that are independent of $\phi_{0}$. The theory for the scattering of light was developed by Debye ${ }^{29}$ who defined the turbidity of a solution, $\tau$, in terms such that $\phi_{1} / \phi_{0}$ $=\exp (-\tau l)$, where $l$ is the path-length in the scattering medium, $\phi_{0}$ is the incident radiant flux and $\phi_{1}$ is the transmitted radiant flux, and deduced that,
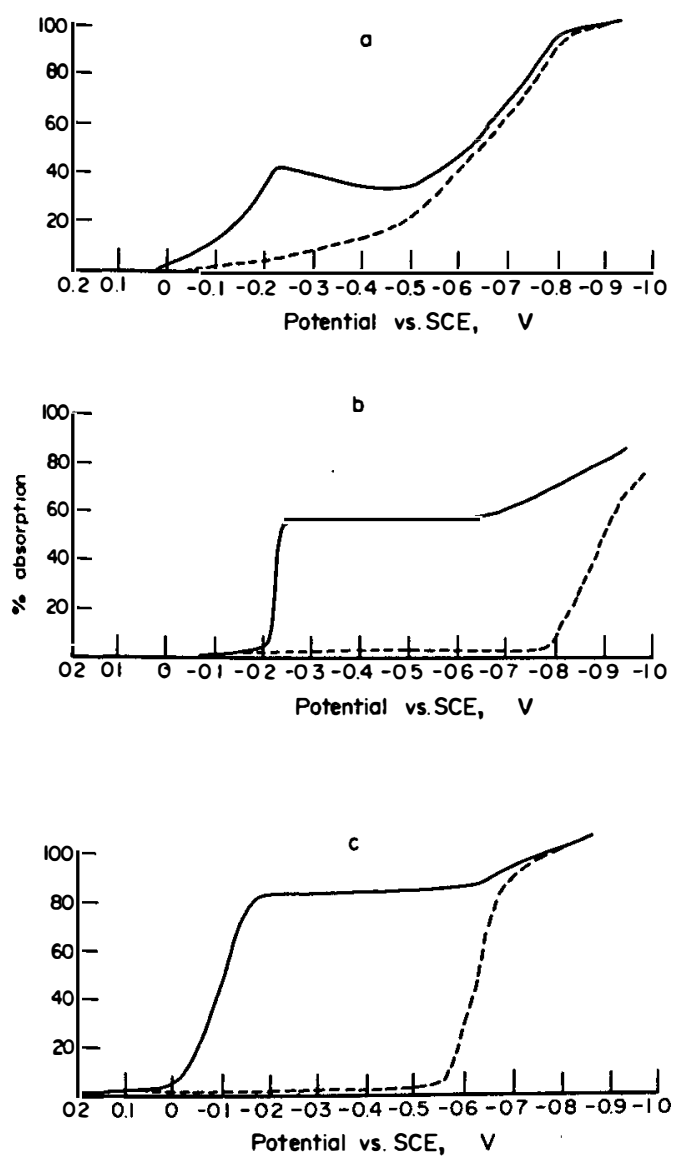

Fig. 7. Variation of $\%$ absorption with potential (vs. SCE) for (a) blank solution at $198 \mathrm{~nm}$, (b) $20 \mathrm{ppm} \mathrm{Cd}^{2+}$ at $215 \mathrm{~nm}$, (c) $0.001 \%$ phenolphthalein at $552 \mathrm{~nm}$, Continuous

line; oxidized surface, Broken line; oxide-free surface. at high dilution, $\tau=K c / \lambda^{4}$, where $K$ is a constant, $c$ is the concentration and $\lambda$ is the wavelength: thus $\ln \left(\phi_{0} / \phi_{1}\right)=K c l / \lambda^{4}$. The Beer-Lambert law for absorption predicts that $\ln \left(\phi_{0} / \phi_{1}\right)=k c l$, and thus the absorbance, defined as $\log \left(\phi_{0} / \phi_{1}\right)$ will be independent of the incident radiant flux whether the light beam is attenuated by true absorption or Rayleigh scattering. The problem of distinguishing between these two phenomena has been discussed as long ago as 1946 by Heller and Vassy, ${ }^{30}$ who proposed distinguishing between them on the basis of the value of the wavelength exponent, $n$, in the equation $k=K \lambda^{-n}$, where $k$ is the absorption coefficient. They deduced that for true absorption $n$ may vary between 0 and $\pm \varkappa$, whereas for scattering, $n$ may vary between 0 and 4. Furthermore, for true absorption $n$ changes rapidly with wavelength, whereas for scattering $n$ changes only very slightly over spectral ranges of up to $100 \mathrm{~nm}$. The values of $n$ for the spectrum obtained with a 10-ppm cadmium solution (uncorrected for the absorption obtained with the background electrolyte alone) were found by plotting log (absorbance) against $\log \lambda$, assuming the absorbance to be proportional to the absorption coefficient. The values obtained varied from -23 at $195 \mathrm{~nm}$ through 0 at $201 \mathrm{~nm}$ to +23 at $275 \mathrm{~nm}$. These values do not rule out the possibility of colloidal material being pro'duced at the electrode, as it is known that colloidal solutions can absorb light according to the BeerLambert law. ${ }^{31}$

It was originally suggested that the absorbing species might be an intermediate in the process of deposition of the metal onto the platinum surface. ${ }^{32}$ There are two problems associated with this theory, the first of which is thermodynamic.

The accessible potential range in the system is governed by the potential at which hydrogen gas is evolved from the working electrode, obscuring the light-beam. The sum of the IR drop and oxygen evolution overvoltage was calculated from the potential difference at which hydrogen was observably evolved, and this, in turn, was used to calculate the deposition potential for $10^{-4} M$ solutions of the metal ions studied. These values are given in Table 4. It can 
Table 3. Variation of absorbance with $\mathrm{pH}$

\begin{tabular}{ccccc}
\hline $\begin{array}{c}\text { Sulphuric acid } \\
\text { conc., } M\end{array}$ & $\begin{array}{c}\text { Initial potential, } \\
V \text { vs. SCE }\end{array}$ & $\begin{array}{c}\text { Final potential, } \\
V \text { vs. SCE }\end{array}$ & $\begin{array}{c}\text { Cd } \\
\text { absorbance, } \\
\text { at } 220 \mathrm{~nm}\end{array}$ & $\begin{array}{c}\text { Blank absorbance } \\
\text { at } 195 \mathrm{~nm}\end{array}$ \\
\hline $\begin{array}{c}\text { none added } \\
10^{-5}\end{array}$ & +0.2 & -0.2 & 0.40 & 0.46 \\
$10^{-4}$ & +0.2 & -0.2 & 0.00 & 0.36 \\
$10^{-3}$ & +0.2 & -0.2 & 0.00 & 0.00 \\
$10^{-2}$ & +0.2 & -0.2 & 0.00 & 0.00 \\
$10^{-5}$ & +0.2 & -0.2 & 0.00 & 0.00 \\
$10^{-4}$ & +0.6 & -0.2 & 0.41 & 0.47 \\
$5 \times 10^{-3}$ & +0.6 & -0.2 & 0.22 & 0.34 \\
$10^{-3}$ & +0.6 & -0.2 & 0.04 & 0.05 \\
& +0.6 & -0.2 & 0.00 & 0.00 \\
\hline
\end{tabular}

be seen that a number of metals $(\mathrm{Ni}, \mathrm{Co}, \mathrm{Cd}, \mathrm{Fe}$, $\mathrm{Cr}, \mathrm{Zn}, \mathrm{Mn}$ ) would not be deposited within the accessible potential range. However, it has long (if not widely) been known that monolayer or submonolayer amounts of metals are deposited at "underpotentials", ${ }^{33}$ i.e., at potentials more anodic than those calculated here. The reason for this is that the full Nernst equation includes a term to account for the activity of the deposit, through energy changes at the electrode-deposit interface. ${ }^{34,35}$ The phenomenon has been extensively studied experimentally, initially by the use of the twin-electrode thin-layer cell developed by Schmidt et al. (see for example ref. 36) and more recently by the combination of spectroscopic tech. niques which monitor the nature of the electrode surface (such as ellipsometry and specular reflection spectroscopy) and electrochemical methods (see for example ref. 37). Experimental methods and results have recently been reviewed, ${ }^{38,39}$ and it appears that underpotentials of between 0.3 and $0.6 \mathrm{~V}$ are observed
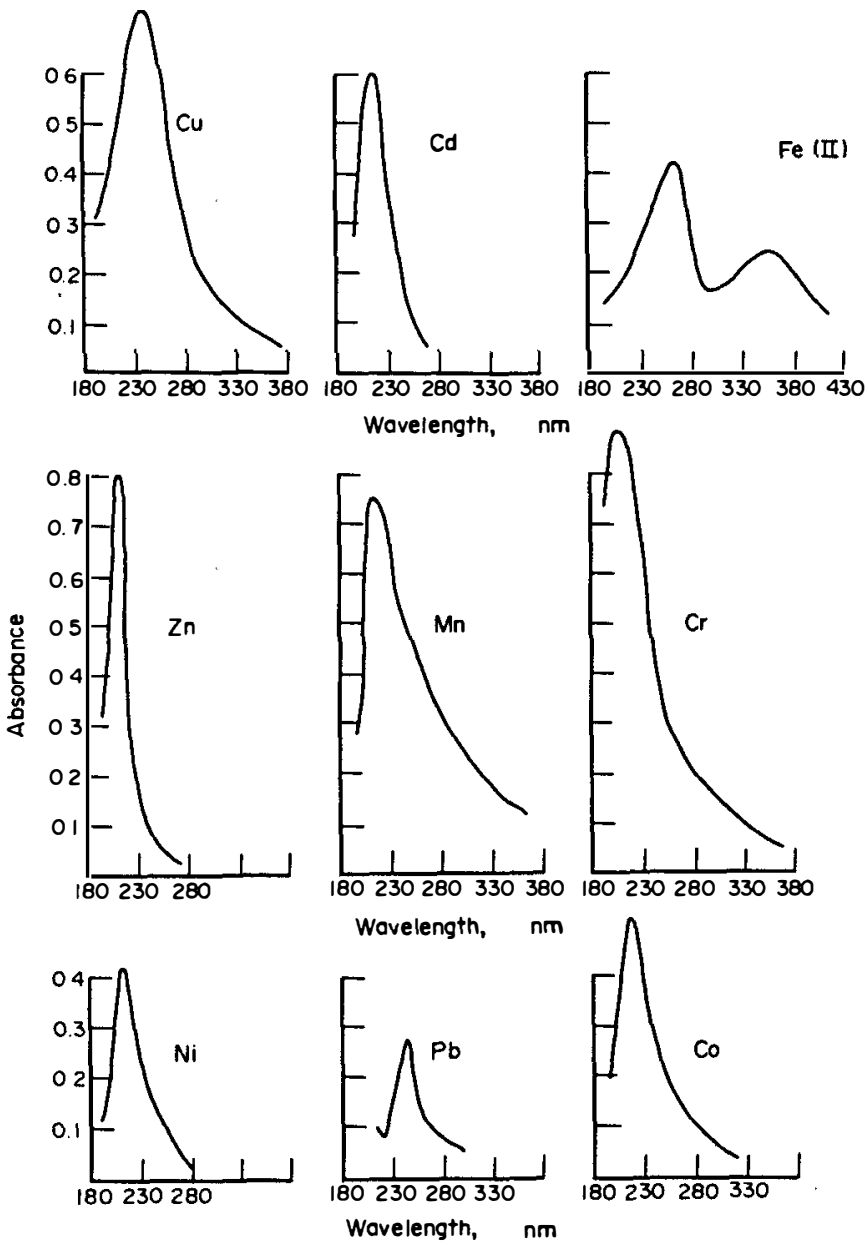

Fig. 8. Absorption spectra of metal ion solutions $10^{-3} \mathrm{M}$ in $\mathrm{KOH} . \mathrm{Cu}, \mathrm{Cd}, \mathrm{Zn}, \mathrm{Mn}, \mathrm{Ni}$ and $\mathrm{Co}$, $10 \mathrm{ppm}$ : $\mathrm{Fe}(\mathrm{II}), \mathrm{Cr}, 5 \mathrm{ppm}, \mathrm{Pb} 20 \mathrm{ppm}$. 
Table 4. Decomposition potentials

\begin{tabular}{lrc}
\hline Ion discharged & $E^{0}, V$ & $E_{\text {deconip }}, V$ \\
\hline $\mathrm{H}^{+}$(pH 6) & 0.00 & 2.20 \\
$\mathrm{Ag}^{+}$ & 0.80 & 1.16 \\
$\mathrm{Hg}^{2+}$ & 0.85 & 1.21 \\
$\mathrm{Cu}^{2+}$ & 0.34 & 1.62 \\
$\mathrm{Fe}^{3+}$ & -0.04 & 1.96 \\
$\mathrm{~Pb}^{2+}$ & -0.13 & 2.09 \\
$\mathrm{Sn}^{2+}$ & -0.14 & 2.10 \\
$\mathrm{Ni}^{2+}$ & -0.25 & 2.21 \\
$\mathrm{Co}^{2+}$ & -0.28 & 2.24 \\
$\mathrm{Cd}^{2+}$ & -0.40 & 2.36 \\
$\mathrm{Fe}^{2+}$ & -0.44 & 2.40 \\
$\mathrm{Cr}^{3+}$ & -0.74 & 2.76 \\
$\mathrm{Zn}^{2+}$ & -0.76 & 2.72 \\
$\mathrm{Mn}^{2+}$ & -1.18 & 3.24 \\
\hline
\end{tabular}

for electrode materials such as gold, silver and platinum. If the potentials calculated in Table 4 were too large by $0.6 \mathrm{~V}$, then up to a monolayer of the metals could be deposited within the accessible potential range.

The second problem with this theory is mechanistic, namely, at what stage in the reduction process absorbing entities are produced at large distances (in terms of the double-layer thickness) from the cathode surface or with sufficient lifetimes and in sufficient amounts to diffuse away from the electrode surface and interact measurably with the light-beam.

Despite the vast amount that has been written about the deposition of metals from aqueous solutions, it is difficult to discover the mechanism inrolved as opposed to an analysis of the process from a kinetic viewpoint. At present authors appear to farour a mechanism the initial steps of which are based on the mechanism of hydrogen evolution (which has been well characterized ${ }^{40}$ ) namely, that after transport to the electrified interface, vibration of the ion within the surrounding water molecules (solvation sheath) produces a condition under which an electron can be transferred from the Fermi level (modified by the application of a cathodic potential) in the electrode to the ion by a process of quantum mechanical tunnelling. ${ }^{41}$

The next stage in the process is not clearly defined. According to Bockris and Damjanovic ${ }^{42}$ the partially neutralized hydrated entity is adsorbed onto the electrode surface (they refer to this entity as an adion), which then undergoes a two-dimensional randomwalk process accompanied by successive diminution in hydration and successive increase in the number of electrode metal atoms which co-ordinate the particle under consideration, until the ion is eventually incorporated into the electrode crystal lattice. It is not clear how or when the second electron is transferred. Bockris has more recently considered the problem $^{43}$ and considers that there is good experimental evidence that mechanisms involving univalent intermediates prevail. This presumably means that the second electron is transferred to a species in solution and that there is the possibility of a homogeneous redox reaction (disproportionation) occurring which would produce neutral hydrated species as well as the original doubly-charged hydrated species:

Recently, the mechanism of charge transfer in the hydrogen evolution reaction has been the subject of some discussion following Walker's presentation of evidence for the involvement of hydrated electrons as precursors in this reaction. ${ }^{44}$ The status of solvated electrons in aqueous electrochemical reactions has been examined closely and the $\operatorname{pros}^{45}$ and cons ${ }^{46}$ debated with some vigour, and it is apparent that the question is not yet resolved. If the absorbing species were produced from the reaction between hydrated ions and hydrated electrons then it would be expected that spectra would be similar to those observed when metal ions react with hydrated electrons produced by radiolysis (the usual and original method of production). Such a study was made by Baxendale et al ${ }^{47}$ who recorded the ultraviolet/visible spectra of species generated when metal ions (including $\mathrm{Cu}^{2+}, \mathrm{Cd}^{2+}, \mathrm{Ni}^{2+}, \mathrm{Co}^{2+}, \mathrm{Zn}^{2+}, \mathrm{Pb}^{2+}, \mathrm{Ag}^{+}$) reacted with hydrated electrons produced by a $2-\mu \mathrm{sec}$ pulse of 4-MeV electrons from a linear accelerator. They found that all the spectra of the transient species produced were similar with an absorbance maximum at around $310 \mathrm{~nm}$.

None of these mechanisms for the production of the absorbing species as an intermediate in the electrodeposition reaction accounts for the involvement of the electrode surface observed here and the considerable effect that the nature of the surface has on the magnitude of the signals. As was indicated earlier, the surface of the platinum could be either oxidized or reduced (oxide-free). The anodic film on platinum has been extensively studied by a wide variety of experimental techniques including spectroelectrochemical methods ${ }^{3}$ and the literature has been comprehensively reviewed. ${ }^{48-50}$ Although there is still some doubt over the nature of the film (which in any case varies with the potential) it may be considered that, under the conditions employed here, the surface of the oxidized electrode would be covered with platinum oxide phases rather than adsorbed oxygen species. What is of greater interest is the mechanism of reduction of this oxide layer and the products of the reduction, i.e., what happens to the surface when a cathodic potential is applied. Despite the many different formulations of the oxide phases, it appears to be generally accepted that in acid solution the final stage in the reduction is

$$
\mathrm{PtOH}+\mathrm{H}^{+}+\mathrm{e}^{-} \rightarrow \mathrm{Pt}+\mathrm{H}_{2} \mathrm{O}
$$

(see for example refs. 49,51 ).

The results of the experiments with phenolphthalein solution indicate that in the potential region in which the surface oxide is reduced, i.e., between 0.0 and $-0.2 \mathrm{~V}$ vs. SCE, (see Fig. 7) the solution near the electrode becomes alkaline when an oxidized elec- 
trode surface is used. If a reduced electrode surface is used then no hydroxide ion is produced in this potential region. It is proposed that the absorbance obtained with the background electrolyte alone is due to $\mathrm{OH}^{-}$. Confirmation was obtained by comparing the absorption spectrum (Fig. 5) with that of a solution of potassium hydroxide. What also emerges from Fig. 7 is that at more negative potentials (from about -0.5 to $-0.6 \mathrm{~V}$ ) there is another process producing $\mathrm{OH}^{-}$near the electrode. Hydrogen evolution did not obscure the light-beam until the potential was greater than $-0.8 \mathrm{~V}$. It is suggested that this is the first stage in the reduction of water to hydrogen, which is adsorbed by the platinum electrode and thus does not obscure the light-beam, and hydroxyl ion.

It is clear from the results that the absorption of light observed when the metal ion solutions are electrolysed is connected directly with the production of an alkaline layer next to the cathode surface. This is shown by Fig. 7 and from the fact that when the solution is made increasingly acid, thus reducing the thickness of the alkaline layer, the observed absorbance decreases and eventually disappears altogether (Table 3). The absorption spectra obtained on adding potassium hydroxide to the metal ion solutions (Fig. 8) are very similar to those obtained at the electrode surface (Fig. 4). Thus it is concluded that the absorbance is due to the production of hydroxo-complexes adjacent to the cathode, following the production of hydroxyl ions. The overall mechanism proposed is:

1. Reduction of the surface oxide layer to give $\mathrm{OH}^{-}$ in solution near the cathode.

2. $\mathrm{OH}^{-}$diffuses into the solution under the concentration gradient.

3. Metal ions in the solution react rapidly to form the hydroxo-complexes which give rise to the absorbances measured.

4. As the surface oxide is removed the production of $\mathrm{OH}^{-}$decreases and eventually ceases.

5. Correspondingly, the absorbance decreases as the hydroxo-complexes dissociate, and diffuse out of the light-path.

That this increase in alkalinity of the catholyte has not been reported more often in the literature is attributed to the fact that most electrochemical studies are made in fairly acid or fairly alkaline solutions. In neither of these solutions would the phenomenon be observed.

\section{Analytical applications}

In effect, the technique developed is a solution spectrophotometric method using electrogenerated hydroxyl ions as a general spectrophotometric reagent. Hydroxide ion has not found use as a spectrophotometric reagent for two reasons; first the absorption of the resulting metal hydroxo-complex lies in the ultraviolet and secondly, and more important, with many metals an insoluble hydroxide precipitates, which would give rise to extremely poor precision.
However, under the conditions employed here, the formation of the complex is controlled by the dyna mic conditions in the diffusion layer next to the cattode and good reproducibility is obtained. The value for the molar absorptivities of the hydroxo-complexs are similar to those for the metal complexes of other general colorimetric reagents such as 8-hydrox!quinoline and diethyldithiocarbamate. The method is applicable only to those metals which form absorbing hydroxo-complexes, but is not restricted to those reducible in the potential range accessible and has the advantages that addition of external reagents. waiting for the colour to develop, etc. are not necessary. Control of the potential of the working electrode controls the $\mathrm{pH}$ in the diffusion layer to a certain extent but is unlikely to offer much in the way of introducing selectivity to the method. It would seem feasible to apply the method to the detection of metat ions following separation, for example by chromatography. Recently the ultraviolet monitoring of metal chloride complexes has been suggested as a method of detection in chromatography. ${ }^{52}$ Use of a suitably designed cell and electrogenerated hydroxide would offer advantages of selectivity and sensitivity over the use of chloride.

Acknowledgements - One of us (JFT) gratefully acknowi. edges financial support from the Science Research Counci and Technicon International.

\section{REFERENCES}

1. Advan. Electrochem. Electrochem. Engineering, Vol. 9. R. H. Muller, ed., Wiley, New York, 1974.

2. J. Kuwana and N. Winograd, in Electroanal. Chem. Vol. 7, A. J. Bowd, ed., Dekker, New York, 1974.

3. Symposia of the Faraday Society, No. 4, London, 1970.

4. A. Yildiz, P. T. Kissinger and C. N. Reilley, And. Chem., 1968, 40, 1018.

5. W. R. Heineman, ibid., 1971, 43, 1075.

6. Idem, ibid., 1972, 44, 1972.

7. F. Möllers and R. Memming, Ber. Bunsenges. Phys. Chem., 1972, 76, 469.

8. H. A. Laitinen, C. A. Vincent and T. M. Bednarski J. Electrochem. Soc., 1968, 115, 1024.

9. O. Elliot, D. L. Zellmer and H. A. Laitinen, ibid., 1970 117, 1343.

10. M. Petek, T. E. Neal and R. W. Murray, Anal. Chem. 1971, 43, 1069.

11. N. J. Hawick, J. Phys. Chem., 1960, 64, 1110.

12. W. N. Hansen, Spectrochim. Acta, 1965, 21, 819.

13. T. Kuwana, R. K. Darlington and D. W. Leedy, Anal. Chem., 1969, 36, 2023.

14. J. W. Strojek and T. Kuwana, J. Electroanal. Chem. $1968,16,471$.

15. T. Kuwana, Ber. Bunsenges. Phy's. Chem., 1973, 77, 888.

16. A. T. Hubbard and F. C. Anson, in Electroanal. Chem. Vol. 4, A. J. Bard, ed., Dekker, New York, 1970.

17. C. N. Reilley, Ret. Pure Appl. Chem., 1968, 18, 137.

18. R. W. Murray, W. R. Heineman and G. W. O'Dom. Anal. Chem., 1967, 39, 1666.

19. N. H. Hansen, R. A. Osteryoung and T. Kuwana, J. Am. Chem. Soc., 1966, 88, 1062.

20. W. H. Hansen, R. A. Osteryoung and T. Kuwana Anal. Chem., 1966, 38, 1810.

21. G. C. Grant and T. Kuwana, J. Electroanal. Chem, 1970, 24, 11. 
22 J. F. Tyson and T. S. West, Nature, 1974, 250, 139.

23. S. Gilman, in Electroanal. Chem., Vol. 2, A. J. Bard, ed., p. 111. Dekker, New York, 1967.

24. M. Breiter, Electrochim. Acta, 1903, 8, 925.

25. C. V. King, J. Electrochem. Soc., 1955, 102, 195.

26. P. G. Hansen, J. Inorg. Nucl. Chem., 1959, 12, 30.

27. Idem, ibid., 1961, 17, 232.

28. L. B. Harris, J. Electrochem. Soc., 1973, 120, 1034.

29. P. Debye, J. Phys. Coll. Chem., 1947, 51, 18.

30. W. Heller and E. Vassy, J. Chem. Phys., 1946, 14, 565.

31. B. Jirgensons and M. E. Strausmanis, $A$ Short Textbook of Colloid Chemistry, p. 119. Pergamon, London, 1962.

32. T. S. West, Analyst, 1974, 99, 886.

33. L. B. Rogers and A. F. Stehny, J. Electrochem. Soc., $1949,95,25$.

34. J. T. Byrne and L. B. Rogers, ibid., 1951, 98, 457.

35. M. M. Nicholson, J. Am. Chem. Soc., 1957, 79, 7.

36. E. Schmidt and H. R. Gygax, Helv. Chim. Acta, 1966, 49, 733, 1105.

37. D. M. Kolb, Farad. Disc. Chem. Soc., 1973, 56, 138.

38. W. J. Lorenz, H. D. Hermann, N. Wüthrich and F. Hibbert, J. Electrochem. Soc., 1974, 121, 1167.

39. D. M. Kolb, M. Pvzasnyski and H. Genoher, J. Electroanal. Chem., 1974, 59, 25.

40. D. B. Matthews and J. O'M. Bockris, in Modern Aspects of Electrochemistry, Vol. 6, J. O'M. Bockris and B. E. Conway, eds., Butterworths, London, 1971.
41. J. O'M. Bockris and A. K. N. Reddy, Modern Electrochemistry, Vol. 2, MacDonald, London, 1970.

42. J. O'M. Bockris and A. Damjanovic, in Modern Aspects of Electrochemistry, Vol. 3, J. O'M. Bockris and B. E. Conway, eds., Butterworths, London, 1964:

43. J. O'M. Bockris and H. R. Despic, in Physical Chemistry, An Advanced Treatise, H. Eyring, D. Hendersen and N. Jost, eds., Vol. 1XB, Academic Press, London, 1970.

44. D. C. Walker, Can. J. Chem., 1967, 45, 807.

45. G. A. Kenney and D. C. Walker, in Electroanal. Chem., Vol. 5, A. J. Bowd, ed., p. 15. Dekker, New York, 1971.

46. B. E. Conway, in Modern Aspects of Electrochemistry, Vol. 7, J. O'M. Bockris and B. E. Conway, eds., p. 83. Butterworths, London, 1972.

47. J. H. Baxendale, E. M. Fielden and J. P. Keene, Proc. Roy. Soc. (London), 1965, A286, 320.

$48 \mathrm{~J}$. P. Hoare, in Adv. Electrochem. Electrochem. Engineering, Vol. 6, P. Delahay, ed., p. 201. Interscience, New York, 1967.

49. A. Damjanovic, in Modern Aspects of Electrochemistry, Vol. 5, J. O’M. Bockris and B. E. Conway, eds., p. 369. Plenum Press, New York, 1969.

50. A. J. Appleby, ibid. Vol. 9, 1974, p. 369.

51. B. V. Tilak, B. E. Conway and H. Angerstein-Kozlowska, J. Electroanal. Chem., 1973, 48, 1.

52. L. Goodkin, M. D. Seymour and J. S. Fritz, Talanta, 1975, 22, 245. 